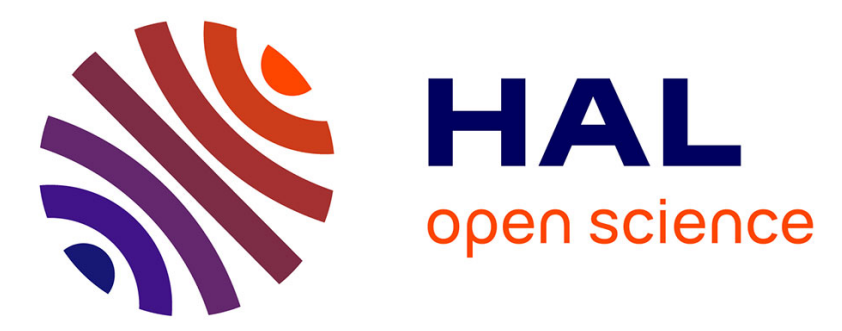

\title{
Maintenance as a cornerstone for the application of regeneration paradigm in systems lifecycle
}

Laëtitia Diez, Pascale Marangé, Frédérique Mayer, Eric Levrat

\section{To cite this version:}

Laëtitia Diez, Pascale Marangé, Frédérique Mayer, Eric Levrat. Maintenance as a cornerstone for the application of regeneration paradigm in systems lifecycle. Sixth International Conference on Complex Systems Design \& Management, CSD\&M 2015, Nov 2015, Paris, France. pp.185-197, 10.1007/978-3319-26109-6_14. hal-01236850

\section{HAL Id: hal-01236850 https://hal.science/hal-01236850}

Submitted on 2 Dec 2015

HAL is a multi-disciplinary open access archive for the deposit and dissemination of scientific research documents, whether they are published or not. The documents may come from teaching and research institutions in France or abroad, or from public or private research centers.
L'archive ouverte pluridisciplinaire HAL, est destinée au dépôt et à la diffusion de documents scientifiques de niveau recherche, publiés ou non, émanant des établissements d'enseignement et de recherche français ou étrangers, des laboratoires publics ou privés. 


\title{
Maintenance as a Cornerstone for the Application of Regeneration Paradigm in Systems Lifecycle
}

\author{
Laëtitia Diez ${ }^{1}$, Pascale Marangé ${ }^{1}$, Frédérique Mayer $^{2}$, and Eric Levrat ${ }^{1}$ \\ ${ }^{1}$ CNRS, CRAN UMR 7039, France, Université de Lorraine, CRAN UMR 7039, boulevard des aiguillettes BP 70239, F- \\ 54506 Vandoeuvre \\ ${ }^{2}$ Université de Lorraine/ENSGSI, ERPI, EA no 3767, 8 rue Bastien Lepage, 54010 Nancy, France \\ \{laetitia.diez, pascale.marange, eric.levrat, frederique.mayer\}@univ-lorraine.fr
}

\begin{abstract}
The circular economy is an economy, firstly, considering the natural resources as finite and the nonexistence of waste, secondly, assimilating the industrial system as a natural system and, finally, emphasizing the paradigm of regeneration. Nevertheless, this paradigm is not clearly defined and this paper aims to found it by proposing solutions to its implementation in the industrial world. The proposal is based on a comparison between the natural system and the industrial system by using the trophic organization model and their elements. Then, the maintenance process is seen as a key element of regeneration. Finally, the notion of nutrient is studied and taken into account in an industrial process.
\end{abstract}

Keywords: Sustainable development, circular economy, regeneration, system lifecycle, maintenance

\section{Introduction}

Further to the analysis on the climate change, the greenhouse gases, the exhaustion of the natural resources and the increase of waste..., the European political powers have implemented a strategy titled "Europe 2020" [1]. Just like for the United Nations Conference on Sustainable Development (UNCSD) or Rio+20, this strategy is based on the three pillars (economy, environment, social) of sustainable development. This development is defined as a "development that meets the needs of the present without compromising the ability of future generations to meet their own needs" [2] and aims to change the economy.

Faced with this development, the linear model (take-make-dump) becomes obsolete and gives way to circular model (make-use-return infinitely). This new economy is increasing and is promoted by diverse organization, such as the "Ellen MacArthur Foundation" in United Kingdom, the "Institut de 1'Economie Circulaire" in France, the international certification "Cradle to Cradle ${ }^{\circledR}$ ", etc.

The circular economy considers that the natural resources exist in finite quantities and that the waste do not exist [3]. Thus, the general idea is to create closed loops by reusing constantly the manufactured goods, based on the system thinking, the use of renewable resources and the fact that waste equal resources. This approach forces us to change the paradigm and to move towards the "regeneration" paradigm. This one relies on several schools of thought, like:

- Biomimicry [4] is the study of nature to design goods and systems in a sustainable way. This concept has promoted products. For example, the high-speed train is inspired by the form of some birds, the glue by the adhesive capacity of mussels, the swimsuit by the skin of sharks, the new energy production by the photosynthesis, etc.;

- Industrial Ecology [5] is the study of material and energy flows through the industrial system to add value to waste from one firm as resources for one or more other firms. This concept rely on the optimization calculations and on the Life Cycle Analysis. Industrial Ecology considers the industrial system as an ecosystem to create a closed-loop operating as the nature [6]. The Kalundborg area [7] is a good example of industrial symbiosis, which aims to optimize the water use, to save energy and to reuse waste;

- Regenerative Design is the study of environment and community of a place to design in harmony with them [8]. This design involves seeing the environment, the community, and the systems as a whole [9]. This design goes further than the sustainable design in regenerating the end-of-life systems. A product is regenerative if and only if it is $100 \%$ recycled and recyclable and improves the environmental and human conditions; 
- Cradle to Cradle [10] is the popular term of regenerative design and uses a biomimicry approach to design goods. This concept considers the materials as nutrients (organic and technical). The biological nutrients are organic materials that can return healthily in the natural cycle. The technical nutrients are non-toxic, nonharmful synthetic materials for the natural environment, but they cannot return in the biosphere and must go back in the technical cycle.

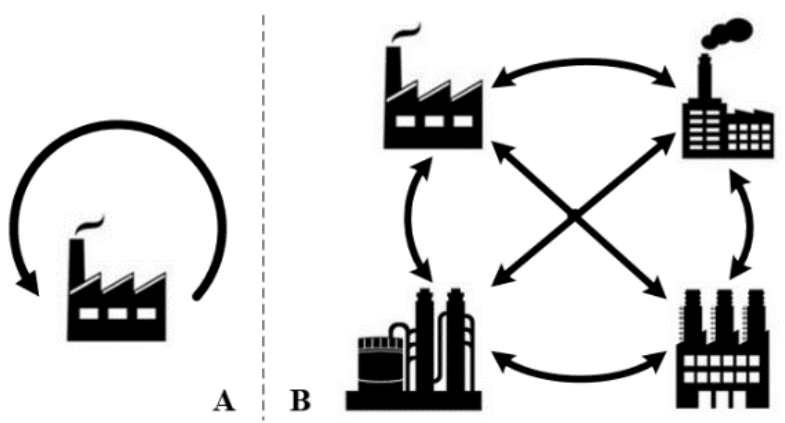

Fig. 1. Auto-Regeneration (A) and Regeneration by network of companies (B)

With all this concepts, the regeneration paradigm is difficult to set up. Indeed, in the best-case scenario, every firm would be able to regenerate its own goods and waste to produce new secondary matters and energy (Fig.1.A). This is workable by the future companies, but for the existing firms, this is more difficult. Creating firms networks is an interesting idea. Each of these firms is able to regenerate the goods of one or several companies and to consume the energy produces by itself or other companies (Fig.1.B).

The purpose of this paper is to determine if the regeneration paradigm is relevant to the industrial world and to propose a way to develop it in the industry, based on the maintenance process.

For this, the section 2 describes, first, what is the regeneration in nature through the food web and, secondly, transposes the trophic organization to the industrial world. Then section 3 identifies the processes, which allow regenerating a nutrient in the product lifecycle. The section 4 defines the elements necessary to nutrient regeneration. A discussion/conclusion is proposed in section 5.

\section{Regeneration Concept}

Currently, biosphere and technosphere (part of biosphere affected by modifications of the human origin) are seen completely independently of one another. However, in the reality and from the point of view of the circular economy, the biosphere contains the technosphere, which affects constantly this first. In fact, the technical cycle of the technosphere affects the natural cycle, which evolves in the biosphere. To understand these influences, the different elements allowing the interaction of cycles and their regeneration must be identified.

Biology defines the verb "regenerate" as a process "to grow again". In other words, the nature regenerates continuously and does not know the notion of waste, contrary to the industry. The principle of biomimicry is a good starting point to understand the regeneration paradigm. Especially as, in the biosphere, the exchanges are circular and as the industry uses resources from nature.

\subsection{Natural Regeneration}

The food web is an excellent example of circularity and regeneration. Indeed, Ecology emphasizes that the trophic organization allows at each population of living being to replace each other naturally. This organization is based on the exchange of nutrient organic, mineral and energizing between the trophic levels, i.e., that each living organism feeds it another [11]. A nutrient is a nutritive substance that sustains the life. Actually, vegetables (primary producers) feed of solar energy and mineral nutrients. Herbivores (primary consumers) eat vegetables and the carnivores (secondary consumers) eat herbivores and other carnivores. Each of these categories generates organic matters, which are eaten by decomposers (ex: bacteria, fungi, worms). These decomposers produce mineral nutrients to feed vegetables, and so on and so forth (Fig.2). So all resources regenerate except the solar energy that is a renewable energy for a long time, at the human scale.

In this organization, the fundamental elements are decomposers. In fact, these organisms transform an unusable matter (organic matter) by producers and consumers in another matter (nutrient) usable by vegetables. 
Without them, the trophic organization would not be circular but linear. That would result by an accumulation of organic matters, an exhaustion of vegetables and by the extinction of species.

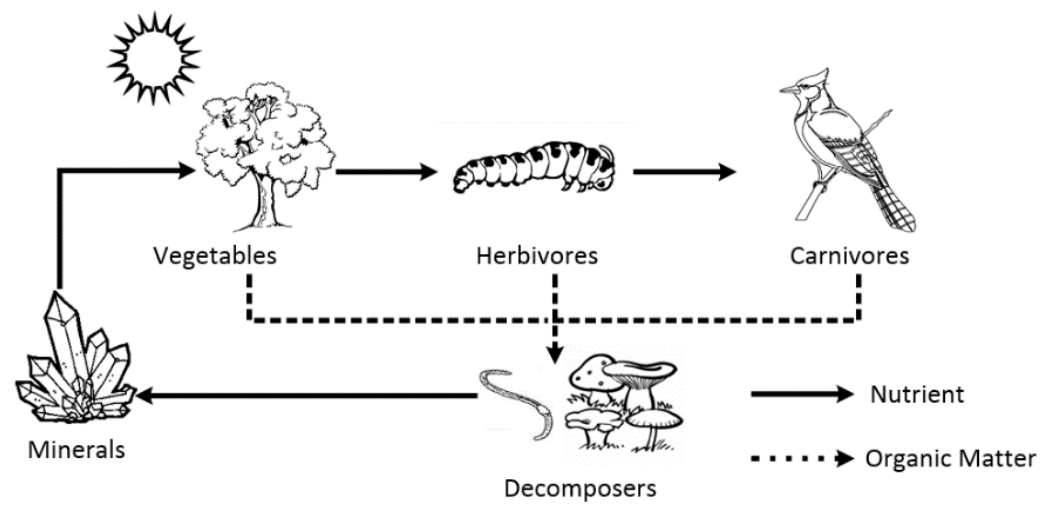

Fig. 2. Trophic organization (Natural)

\subsection{Industrial Regeneration}

Contrary to the natural cycle, the technical cycle is linear. In fact, the firms of primary sector business exploit the resources of nature (organic and mineral) to supply the firms making goods (secondary sector). This sector supplies tertiary sector. Each of those sectors produces waste. Like so, the industrial world accumulates waste and exploits the finite resource of nature, and that is the problem. Indeed, the storage of waste costs much and the natural resources make rare. To solve this problem, the nature must inspire industry. Especially as the nature does not need storage and is able to regenerate its resources.

If one compares the behavior of the natural system with the industrial system, we note that there is no business sector, which treats waste to transform them in the raw material. In the nature, the decomposers play this job. To become regenerative and circular, the industry must organize decomposers.

Thus, the parallel with the nature allows assimilating the primary sector business with the primary producers, the secondary sector with the primary consumers and the humans activities with secondary/tertiary consumers [12]. Decomposers allow regenerating waste from sectors and transforming them in raw secondary matters for each sector or in natural resources for nature and the primary sector (Fig.3).

Moreover, as the biosphere, several living organisms compose the technosphere. A company this is an (artificial) complex system linked and organized. This organism must consume resources, i.e. nutrients, to live, develop and prosper. In the industrial world, resources correspond to materials, energy, services, staff and knowledge. The secondary sector produces objects that are resources, i.e., nutrients for human activities. An object is often a set of objects. Consequently, a nutrient is a set of nutrients.

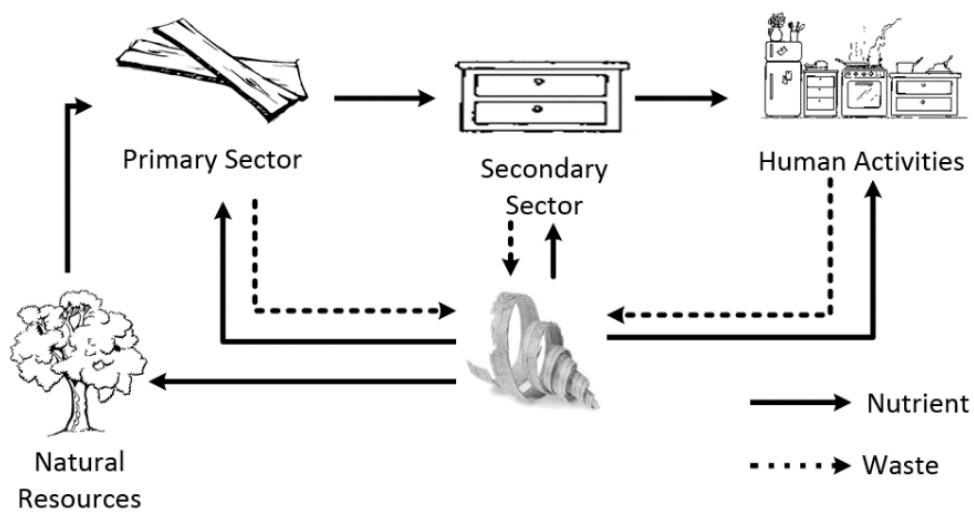

Fig. 3. Trophic organization (Industrial)

Finally, as the trophic organization, business sectors trade nutrients and produce waste regenerated by decomposers. However, these sectors consume different types of nutrients from the biosphere (organic and mineral) and technosphere (technical). Wood and leather are organic nutrients, water and iron are mineral nutrients, and paper and PVC are technical nutrients. 
The natural decomposers can be used to regenerate organic nutrients and to create mineral nutrients for vegetables. Industry must organize technical decomposers to regenerate technical nutrients and to create all natures of nutrients (organic, mineral and technical). The accumulation of mineral nutrients, from technical decomposers, are artificial mines for the primary sector (Fig.4). For this figure, we consider a perfect cycle where all waste are regenerated.

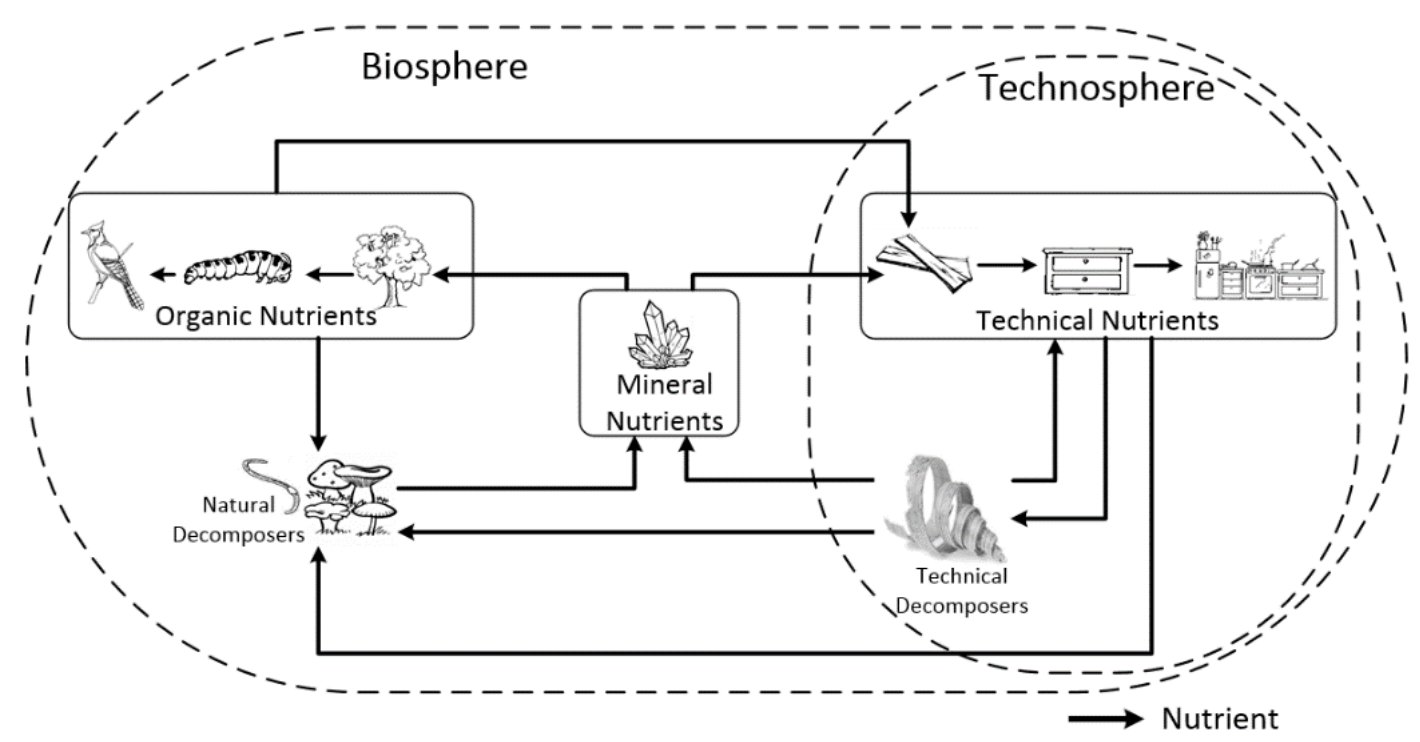

Fig. 4. Interaction between natural and technical cycle

Biosphere and technosphere represent and form a set of ecosystem mutually dependent and accommodate living organisms. In fact, the notion of nutrient allows making a link between the different elements of each cycle and between the cycles themselves. By adding the technical decomposers, in technosphere, the goods become regenerable and allow reducing waste and the exploitation of natural resources. Moreover, the use of natural decomposers to regenerate waste of technosphere allows giving back nutrient to exploit.

\section{Product Lifecycle}

In this part, we concentrate on the secondary sector and more specifically, on the material flows of production (manufacturing, assembly and distribution), operation (utilization and maintenance) and retirement processes. We suppose also that processes exchange nutrients and that the circularity of trophic organization is applicable on the product lifecycle.

Usually, the product lifecycle used in the industry is linear as the technical cycle. Moreover, we can apply the trophic organization on this lifecycle. In fact, the manufacturing process uses nutrients from the primary sector and can be compared with vegetables, assembly process with herbivores (uses nutrients product by manufacturing process), distribution, utilization and maintenance processes with carnivores and retirement process with decomposers. However, contrary to these of natural cycle, the decomposers of lifecycle do not produce nutrients usable by another process. To close the loop, the retirement process must return towards production or better towards the customer.

\subsection{Closed-loops}

$[3,13]$ suggest creating a loop between retirement and all other processes. In other words, the retirement process (technical decomposers) is able to reuse, remanufacture and recycle a nutrient. The maintenance process is also a decomposer, but only replacements, adjustments and repairs actions. Furthermore, in the general system theory [14], a process can be defined in a "time-space-shape" (TSS) frame reference. Nevertheless, this referential is not enough to define a decomposer. In fact, decomposers can alter the nutrient functionality. If we compare a nutrient going in and out process, this nutrient is always affected in the time, may be transported and/or modified on its shape, and may keep its functionality. Moreover, each object by circulating in a process is characterized by "state variable" relating to TSS referential, i.e., temporal, spatial and shape properties [15]. In the same way, as 
for the flows, a nutrient has these properties, which will develop in the next section. Therefore, technical decomposers can be defined as (Fig. 5):

- Replacement/Repair process: transformation of time, and preservation of nutrient functionality;

- Reuse process: transformations of time and space, and preservation of nutrient functionality;

- Remanufacture process: transformations of time, space and shape, and non-preservation of nutrient functionality. But the nutrient parts keep their functionality;

- Recycling process: transformations of time, space and shape, and non-preservation of nutrient functionality. The nutrient parts do not keep their functionality.

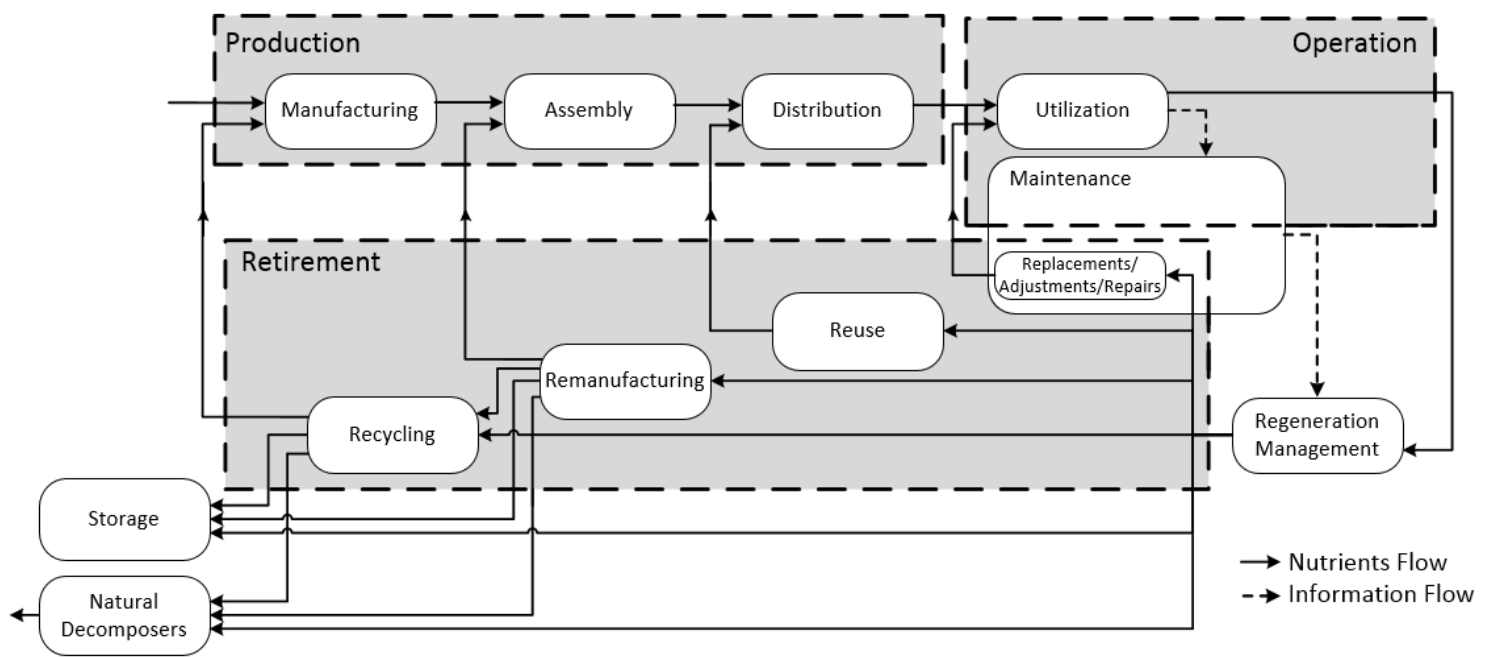

Fig. 5. Closed-loops of product lifecycle

In this list, only technical decomposers are cited to regenerate technical nutrients, but the industry uses also organic nutrients. Natural decomposers must be added at this list to regenerate those nutrients and make transformations of time, space, and shape on organic nutrients, without preservation of nutrient functionality. The vegetables can use these regenerated nutrients. However, with current technologies, a decomposer can regenerate not all nutrients; this nutrient will be stored and kept in the technosphere.

After the identification of decomposers, we must find how to select an appropriate decomposer to regenerate nutrient and determine when regenerating it. A regeneration manager is necessary, and to make this job, we propose to add a regeneration management process (Fig. 5). This process rests on the information provided by the maintenance process. In fact, the maintenance process is a process which aims to fix or restore an item in a state in which it can perform its function with dependability [16]. Therefore, it has information on the system state of health. Moreover, in the product lifecycle, this process is situated between production and retirement phases, i.e., before decomposers, what makes it essential to support the nutrients regeneration management.

\subsection{Example: Washing Machine}

To illustrate the different cycles and decomposers, we are interested in a simple example: a washing machine used by a laundry.

- Replacement/Repair scenario: the washing machine is faulty but can be repaired and uses again by the firm;

- Reuse scenario: the washing machine uses too many resources (water, electricity, detergent) or does not adapt to new requirements of the laundry (cold wash and not hot wash), the quality of washing is deteriorated, etc., in other words, loss of technical, energy and economic performances. Hotels, hospital or old people's home, which need the only functionality of the machine and not its performances can reused this machine. A laundry can become also bankrupt and put its machines on the second-hand market.

- Remanufacturing scenario: the washing machine is faulty (cannot be repaired) or not reusable. The machine is dismantled and transformed in spare parts to remanufacture new machine or other systems;

- Recycling scenario: the washing machine and its spare parts are faulty. After dismantled, the parts are separated by matters and ground. These pieces are used as raw materials to manufacture new products. 


\section{Managing Nutrients}

The regeneration manager must have information on the studied nutrient, in other words, the manager needs properties to identify the nature of nutrient and which decomposers used according to different properties of sustainable development and the market needs (nutrients needed by customers with a good added value). The nutrient has properties from processes so-called technical. However, the nutrient definition focuses mainly on the environmental impacts of the nutrient. This requires introducing ecological properties.

The NIAM/ORM language [17], with NORMA plug-in to Microsoft ${ }^{\circledR}$ Visual Studio ${ }^{\circledR} 2010$ Ultimate, is used to model the link between spheres and nutrient properties. This language allows writing out elementary facts.

\subsection{Definitions}

A nutrient is composed of two types: biological nutrients and technical nutrients. Previously, we have seen that the biological nutrients are organic materials that can return healthy in the natural cycle. However, this definition considers only organic materials while industry uses mineral materials too. To take account of these materials, we will talk about natural nutrients instead of biological nutrients. Regarding the technical nutrients, they are non-toxic, non-harmful synthetic materials for the natural environment, but they cannot return in the biosphere and must stay in the technical cycle. This definition is too restrictive. In this paper, the technical nutrient will be a nutrient non-natural that harms the biosphere that the technical cycle must use as long as possible.

\subsection{Elements to Identify Types of Nutrient}

Two stages are necessary to identify the type of nutrient. In first, we must determine if the nutrient harms or not the biosphere and, if the natural decomposers can regenerate it. For this, environmental properties are linked to the biosphere and ecological properties to nutrient. The two categories of properties are identical. A fixed threshold allows comparing the values of an ecological property (carbon footprint, aquatic toxicity, etc.) of nutrient with the environmental properties (Fig.6). In the Cradle to Cradle ${ }^{\circledR}$ certification, a list of environmental health endpoints [18] is available with threshold varying as the function of certification level desired. This list is based on harmful chemical elements for the environment and human and on their quantities. This certification provides a fulcrum to identify the non-harm of nutrient for the biosphere.

Fig. 6. Modeling of the environmental and ecological properties

In second, we must determine if a nutrient can be regenerated or not by the technical decomposers. For this, the approach is the same for ecological properties but with technical properties (dimensions, weight, global cost, etc.). Their values are compared with the thresholds of regeneration properties (of technosphere) (Fig.7). 
Fig. 7. Modeling of the regeneration and technical properties

In other words, the properties lied to spheres define a nutrient. These properties are compared with the properties of each cycle. However, contrary to thresholds, the values of the nutrient change in the time and all through processes. In fact, the nutrient evolves in the TSS referential and the processes transform it. These affect the properties of nutrient and their values.

After this modeling, we make the distinction between technical and natural nutrient, and between regenerable and non-regenerable nutrient.

\subsection{Types of Nutrient}

Taking into consideration that the nutrient properties can be compared with those of biosphere and technosphere, we have created a generic pattern (Fig.8) to realize this comparison. Thus, if a nutrient of type $\mathrm{N}$ satisfies all properties of given sphere, then the nutrient is type N1, return to the sphere and a decomposer (natural for biosphere and technical for technosphere can regenerated by decomposers) it, else that is a nutrient of type N2. The generic pattern is applied on the nutrient $\mathrm{N} 2$ that becomes nutrient $\mathrm{N}$. This pattern is executed until the obtaining a non-regenerable nutrient by either sphere.

A possible instantiation is to compare nutrient ecological properties with environmental properties. If a nutrient does not satisfy at least one environmental property, then it is a pollutant for the environment and defined as technical, else it is natural and regenerable by natural decomposers. Likewise, if a nutrient respects all regeneration properties, then it is regenerable by the technical decomposers and remains in the technical cycle, else it is a non-regenerable nutrient.

Contrary to $[3,10]$, we consider the existence of "waste" to take account of existing goods and not only on those to design. However, these waste are minimized and must be regenerated a maximum. A non-regenerable nutrient by the technosphere is waste and oblige us to think about its return in the natural cycle.

Fig. 8. Generic pattern to identify the type of nutrient 
A non-regenerable nutrient identified as natural is healthy for the biosphere and can return there. Nevertheless, if the nutrient is technical, then it is harmful. Therefore, a harmful nutrient must necessarily to get good properties back, in other words, be confined until technologies enable correctly regenerated it. A cleansed nutrient will able to return in one of the cycles.

This typology allows knowing the nutrient origin and the cycle able to regenerate the studied nutrient. All types of nutrients are defined in the following list:

- Nutrient: element used in an industrial process;

- Technical nutrient: nutrient harming to the biosphere;

- Natural nutrient: nutrient non-harming to the biosphere that can return there;

- Biological nutrient: natural nutrient of organic origin;

- Mineral nutrient: natural nutrient of mineral origin;

- Regenerable nutrient: nutrient satisfying all technical properties and can return to the technical cycle;

- Non-regenerable nutrient: nutrient not satisfying at least one technical properties,

- Healthy nutrient: natural and regenerable nutrient;

- Harmful nutrient: technical and non-regenerable nutrient.

Of course, a nutrient that is natural and technical-regenerable can return in the two cycles, and this choice will come down to the regeneration manager process.

\section{Discussion - Conclusion}

Observing the natural system allows us to find solutions at currently problems of the industrial system, to identify missing elements to transform a linear economy in a circular economy. The parallel between nature and industry evidence the absence of decomposers in the technical cycle. However, the decomposers are the key of regeneration in the natural cycle. Indeed, they transform the organic matters (living organism waste) in mineral salts, elements used by vegetables to grow. Therefore, to regenerate industrial waste, the industry must develop technical decomposers by using the processes identified by the circular economy. Thus, the maintenance, reuse, remanufacturing and recycling processes are technical decomposers required by technosphere. The maintenance process has also a role of support by providing the information on the nutrient to regeneration management process, which selects the best decomposer for each nutrient. After the nutrient regeneration, it returns in a firm by being based on flows study of industrial ecology. Nevertheless, to reintegrate a cycle, the nutrient must satisfy many properties tied to the sphere. The nutrient properties (technical and ecological) must be measurable to estimate the impact of nutrient on a sphere. In this way, those properties allow us to characterize the nutrient according to its impact on a sphere and, to determine which decomposers (natural or technical) used.

In this paper, we have identified some directions of research to answer the requirements fixed by the sustainable development and the circular economy. In fact, we have defined the notion of nutrient and determined, among others, that the maintenance process plays an important role in the regeneration paradigm. However, making regeneration in technosphere is not so easy. We must consider the two spheres as a whole. This consideration affects all levels of product lifecycle, from design to retirement. For example, an object will be designed to satisfy of nutrient properties, its regeneration; the control/command will control that the used elements to produce an object will not deteriorate the nutrient properties; the maintenance will keep a nutrient in good condition for the regeneration.

A track for these works is to define the technical properties to determine if a nutrient is regenerable or not and which decomposer is the more adapted to regenerate this nutrient. The manager role must be also defining. In the regeneration context, the nutrient manager must know the value of nutrient properties in real time. With this knowledge, it can identify the nutrient category and determine if the nutrient is regenerable by a technical or a natural decomposer. The manager must monitor the nutrient state of health. The alteration of nutrient properties must be anticipated to avoid changing the type of nutrient. For example, a regenerable nutrient must be regenerated before to become non-regenerable. The new maintenance approach from community Prognostic and Health Management (PHM), which predicts the future state of a system, can be used to determine the time when the nutrient will change state. The regeneration manager must also allow selecting a decomposer depending on the nutrient state, enterprise strategy, costs cause by the different regeneration processes, etc. while avoiding the storage of nutrients. Therefore, by taking inspiration from PHM, the maintenance will be able to supply the needed information of RPM (Regeneration Potential Management). 


\section{References}

1. European Commission: Europe 2020 : A strategy for smart, sustainable and inclusive growth. , Brussels (2010).

2. World Commission on Environment and Development: Our Common Future. (1987).

3. Foundation Ellen MacArthur: Report version 1, 2 \& 3 : Towards the circular economy, http://www.ellenmacarthurfoundation.org/

4. Benyus, J.M.: Biomimicry. HarperCollins (2009).

5. Ayres, R.., Ayres, L.W.: A Handbook of Industrial Ecology. Edward Elg (2002).

6. Nielsen, S.N.: What has modern ecosystem theory to offer to cleaner production, industrial ecology and society? The views of an ecologist. J. Clean. Prod. 15, 1639-1653 (2007).

7. Ehrenfeld, J., Gertler, N.: Industrial Ecology in Practice: The Evolution of Interdependence at Kalundborg. J. Ind. Ecol. 1, 67-79 (1997).

8. Du Plessis, C.: Towards a regenerative paradigm for the built environment. Build. Res. Inf. 40, 7-22 (2012).

9. Cole, R.J.: Transitioning from green to regenerative design. Build. Res. Inf. 40, 39-53 (2012).

10. McDonough, W., Braungart, M.: Cradle to Cradle: Remaking the Way We Make Things. Farrar, Straus and Giroux (2010).

11. Kormondy, E.J.: Concepts of ecology. Prentice-Hall (1969).

12. Geng, Y., Côté, R.P.: Scavengers and decomposers in an eco-industrial park. Int. J. Sustain. Dev. World Ecol. 9, 333-340 (2002).

13. Kumar, S., Putnam, V.: Cradle to cradle: Reverse logistics strategies and opportunities across three industry sectors. Int. J. Prod. Econ. 115, 305-315 (2008).

14. Le Moigne, J.-L.: La théorie du système général: théorie de la modélisation. Presses Universitaires de France (1994) (in French)

15. Mayer, F.: Contribution au génie productique : Application à l'ingénierie pédagogique en atelier inter-établissements de productique lorrain. Phd Henri Poincaré University, Nancy (1995) (in French)

16. ISO 13306: Maintenance Terminology (2010).

17. Halpin, T.: Object-Role Modeling (ORM/NIAM). Handbook on Architectures of Information Systems. Chapter 4 (1998).

18. McDonough Braungart Design Chemistry (MBDC): C2C Certified : Material Health Methodology. (2013), http://www.c2ccertified.org/ 